\title{
Elk and Deer Studies Related to the Basalt Waste Isolation Project
}

L. E. Eberhardt

S. M. McCorquodale

G. A. Sargeant

March 1989

Prepared for the U.S. Department of Energy under Contract DE-AC06-76RLO 1830

Pacific Northwest Laboratory Operated for the U.S. Department of Energy by Battelle Memorial Institute 


\title{
DISCLAIMER
}

This report was prepared as an account of work sponsored by an agency of the United States Government. Neither the United States Government nor any agency thereof, nor Battelle Memorial institute, nor any or their employees, makes any warranty, expressed or implied, or assumes any legal liability or responsibility for the accuracy, completeness, or usefulness of any information, apparatus, product, or process disclosed, or represents that its use would not infringe privately owned rights. Reference herein to any specific commercial product, process, or service by trade name, trademark, manufacturer, or othenwise does not necessarily constitute or imply its endorsement, recommendation, or favoring by the United States Government or any agency thereof, or Battelle Mernorial institute. The views and opinions of authors expressed herein do not necessarily state or reflect those of the United States Government or any agency thereof.

\author{
PACIFIC NORTHWEST LABORATORY \\ operated by \\ BATTELLE MEMORIAL INSTITUTE \\ for the \\ UNITED STATES DEPARTMENT OF ENERGY \\ under Contract DE-AC06-76RIO 1830
}

\begin{tabular}{|c|c|}
\hline \multicolumn{2}{|c|}{ Printed in the Uniled States of America } \\
\hline \multicolumn{2}{|c|}{ Available from } \\
\hline \multicolumn{2}{|c|}{ National Technical Information Service } \\
\hline \multicolumn{2}{|c|}{ United Stales Department of Commerce } \\
\hline \multicolumn{2}{|c|}{5285 Port Royal Road } \\
\hline \multicolumn{2}{|c|}{ Springfield, virginia 22161} \\
\hline \multicolumn{2}{|c|}{ NTIS Prire Codes } \\
\hline \multicolumn{2}{|c|}{ Microfiche A01 } \\
\hline \multicolumn{2}{|c|}{ Printed Copy } \\
\hline & Price \\
\hline Pages & Codes \\
\hline $001-023$ & $\mathrm{~A} 02$ \\
\hline $026-050$ & $\mathrm{A03}$ \\
\hline 0.51 .075 & $\mathrm{~A} 04$ \\
\hline $076-100$ & A 05 \\
\hline 101.125 & $A 06$ \\
\hline $126-150$ & A.07 \\
\hline $151-175$ & AOA \\
\hline $176-200$ & $\mathrm{~A} 09$ \\
\hline $20+-225$ & A 10 \\
\hline $226-250$ & A11 \\
\hline $25 r-275$ & A 12 \\
\hline $276-300$ & A.13 \\
\hline
\end{tabular}


PNL-6798

UC-11

ELK AND DEER STUDIES RELATED TO THE BASALT WASTE ISOLATION PROJECT
L. E. Eberhardt
S. M. McCorquodale(a)
G. A. Sargeant

March 1989

Prepared for the U.S. Department of Energy under Contract DE-AC06-76RLO 1830

Pacific Northwest Laboratory

Richland, Washington 99352

(a) Yakima Indian Nation Wildlife Resource Management Toppenish, Washington 



\section{SUMMARY}

A study of elk (Cervus elaphus) and deer (edocoileus hemionus) was conducted in the vicinity of planned site characterization activities for the Basalt Waste Isolation Project (BWIP). These species were selected for study because both are known to be sensitive to disturbance and are considered important species because they are recreationally and/or commercially valuable. The principal objectives of the study, as first designed, were to 1) estimate pre-activity (site characterization) recruitment of deer and elk, 2) characterize deer and elk use of limited habitats critical to their survival (e.g., niparian areas), 3) describe preferential habitat use by deer and elk during critical seasons (i.e., winter and summer), and 4) document pre-activity distributions of seasonal home range centers of deer and elk. Early termination of BWIP prevented some of these objectives from being fully addressed.

Fifteen adult elk (11 females and 4 males) and 19 female deer equipped with radio transmitters were studied on the Arid Lands Ecology (ALE) Reserve from February through December 1987. More than 1,800 relocations of the marked elk and deer were made during aerial and ground tracking sessions.

Deer confined their activities to relatively small areas throughout the study, generally within $2 \mathrm{~km}$ of water sources. In contrast, elk used 6-12 times the average area used by deer. As with deer, female elk were closely associated with available water sources during the summer and fall, presumably because of the physiological demands of lactation. However, during the winter, female elk showed no preference for areas near water, as did male elk throughout the study. Riparian areas, which are scarce on the arid Hanford Site, are particularly valuable habitat to both elk and deer because they provide drinking water and succulent forage during the dry summer and early fall months.

A westward shift in the use of the ALE Reserve was noted for female elk, when compared with data obtained during 1983-84. It is believed that this shift in area of use may be associated with the increased human activity that has occurred in the midwestern portion of the ALE Reserve during the last couple of years. A daily shift in elk use of the ALE Reserve relative to both paved and dirt roads was also noted. Elk spent more time closer to dirt roads than paved roads, where the volume of traffic was higher; however, they approached both types of roads closer during the night than during the day. 
Both species were crepuscular in their daily activity patterns, as measured by distance moved per hour, especially during midsummer and late fall. These peaks were probably related to the high midday temperatures during the summer, the hunting season, and/or breeding activity duning the fall. The level of activity on a monthly basis was also similar for both species.

At least 27 elk calves were born on the ALE Reserve during the study, resulting in a prehunting-season population of slightly more than 100 individuals. A minimum of 14 elk were killed between August and November during hunts on privately owned lands surrounding the ALE Reserve. Reproductive success of marked deer was lower than that of elk, with only $47 \%$ of the marked femaies being observed with young. Twenty percent of the marked female deer died during the study.

The level of engineering and construction activity associated with BWIP duning 1987 was not sufficient to directly assess the responses of elk and deer to disturbance. However, results from this study suggest that niparian areas are particularly important to both species, and distumance to these areas is one of the greatest potential impacts to deer and elk on the Hanford Site. 


\section{ACKNOWLEDGMENTS}

This document was prepared for the U.S. DOE Basalt Waste Isolation Project. In developing these studies, we have drawn extensively on the data base, design paradigms and professional experience of staff associated with predecessor programs funded by the DOE Richland Operations Service Assessment Pool and by the Division of Biomedical and Environmental Sciences of the Department of Energy. 



\section{CONTENTS}

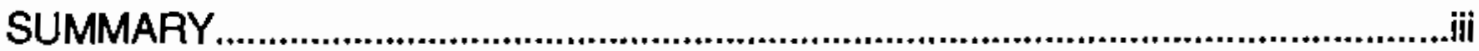

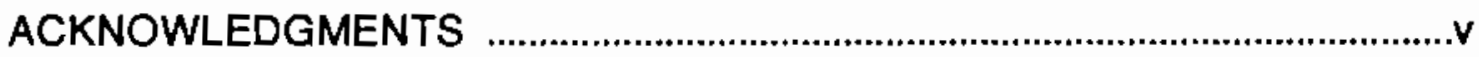

INTRODUCTION

STUDY AREA

METHODS

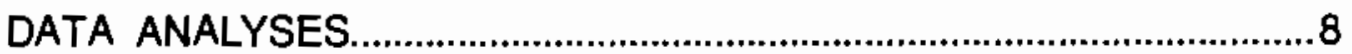

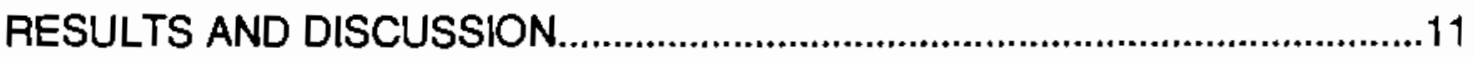

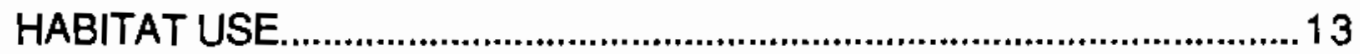

Home Range Use........................................................................13

Use of Riparian Areas and Water Sources................................15

Influence of Roads and Vehicles.................................................19

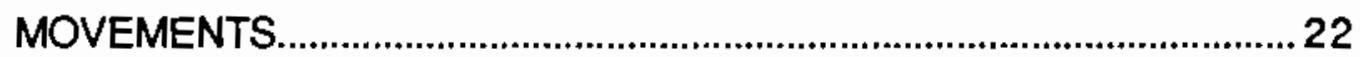

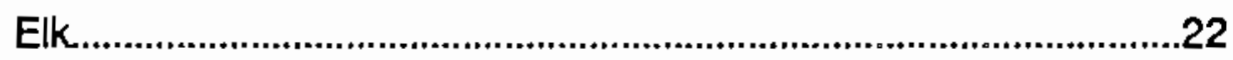

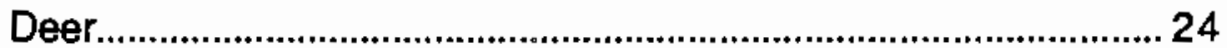

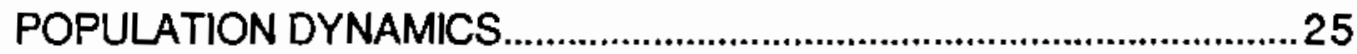

Elk

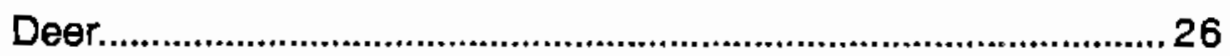

CONCLUSIONS/ENVIRONMENTAL IMPACT CONSIDERATIONS.............29

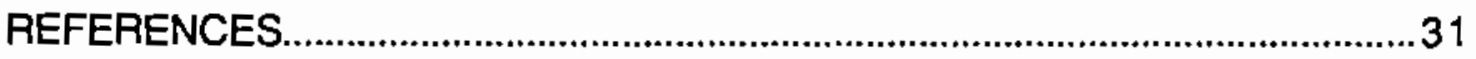

APPENDIX A - SCHEDULE AND SUMMARY OF RADIO-TRACKING 



\section{EIGURES}

1 Basalt Waste Isolation Project Activity Areas and Geographic

Features Near the Deer and Elk Study Area

2 Comparison of the Proportion of Relocations of Radio-Marked

Elk that Fall Within Three Distance Zones Radiating from All

Available Water Sources on the ALE Reserve

3 Comparison of the Proportion of Relocations of Radio-Marked

Deer that Fall Within Three Distance Zones Radiating from

All Available Water Sources on the ALE Reserve

4 Distribution of Relocations of Radio-Equipped Elk Relative to

Distance from Paved and Dirt Roads by Time of Day

5 Comparison of Daily Activity Patterns of Elk and Mule Deer

on the Hanford Site as Measured by Average Distance Moved

6 Companison of Monthly Activity Patterns of Elk on the Hanford Site

During Morning/Evening (0500-0800 and 1800-2200 Hours) and

Midday (0900-1700 Hours) as Measured by Average Distance

Moved

7 Comparison of Monthly Activity Patterns of Mule Deer on the Hanford Site During Morning/Evening (0500-0800 and 1800-2200 Hours) and Midday (0900-1700 Hours) as Measured by Average Distance Moved

\section{IABLES}

1 Elk Radio-Collared on the Hanford Site for BWIP .............................. 11

2 Adult Female Mule Deer Captured on the Hanford Site for BWIP ......... 12

3 Home Range Sizes for Marked Elk Studied on the Hanford Site in 1987

4 Home Range Sizes for Marked Female Deer Studied on the Hanford Site in 1987

5 Summary of the Use of Three Distance Zones from Water by Elk and Deer During the Summer, Fall, and Winter on the ALE

Reserve 
6 Average Distance Moved by Male and Female Elk by Season on the Hanford Site

A.1 Schedule of Intensive Radio-Tracking Conducted on Elk and Deer for the BWIP in 1987

A.2 Summary of Elk Counts Made During Aerial Relocations of Radio-Marked Elk on the ALE Reserve of the Hantord Site 


\section{INTRODUCTION}

On May 28, 1986, the Hanford Site was nominated, with the Yucca Mountain Site in Nevada and the Deaf Smith Site in Texas, as a potential location for the nation's first commercial high-level nuclear waste repository in accordance with the Nuclear Waste Policy Act of 1983 (NWPA). At this time, a period of geotechnical and hydrological investigations, known as site characterization, was begun. The NWPA and the Code of Federal Regulations (10 CFA 960) mandated that environmental protection and environmental impact mitigation be thoroughly addressed during site characterization.

Mule deer (Odocoileus hemionus) and elk (Cerrus elaphus) were known to use areas of the Hanford Site where site characterization activities were planned, and both species are known to be sensitive to disturbance. These species are considered important species by the U.S. Nuclear Regulatory Commission (NRC) criteria because they are recreationally and/or commercially valuable (NRC 1976). In early 1987, Pacific Northwest Laboratory (PNL) initiated studies of mule deer and elk seasonally residing near planned site characterization areas. The principal objectives of these studies, as first designed, were to 1) estimate pre-activity (site characterization) recruitment of deer and elk, 2) characterize deer and elk use of limited habitats critical to their survival (e.g., riparian areas), 3) describe preferential habitat use by deer and elk during critical seasons (i.e., winter and summer), and 4) document pre-activity distributions of seasonal home range centers of deer and elk. Early termination of the project prevented some of these objectives from being fully addressed.

The purpose of this study, as designed, was to determine the influence of site characterization activities on deer and elk populations. Relevant considerations included the numbers of animals seasonally occupying areas near site characterization activities, the relative importance of plant communities and watering areas near these sites to deer and elk, and the availability of alternative areas of important habitat that displaced animals could use. The study was also intended to provide information on potential strategies to reduce impacts of site characterization on deer and elk. The potential use of such information extends beyond the repository program to include any Hanford Site activity that has the potential to adversely affect deer and elk inhabiting the site. 


\section{STUDY AREA}

The study was conducted primarily in the western portions of the Hanford Site near the Exploratory Shaft Site (Figure 1). Of particular concern was the western part of the Arid Lands Ecology (ALE) Reserve where several groundwater wells (DH-22, $\mathrm{DH}-32$, and $\mathrm{DH}-33$ ) were located (Figure 1); this area was thought to be an important wirtering area for Hanford Site deer and elk (McCorquodale 1985a). Deer and elk were monitored beyond the immediate vicinity of known site characterization activity areas because their use of these areas was thought to be seasonal rather than continuous, the radius of disturbance effects associated with site characterization was unknown, and not all site characterization areas had been determined. Additionally, several deer were less intensively monitored near the southcentral boundary of the Hanford Site. These deer were selected to serve as control animals whose behavior could be compared with the behavior of deer residing near site characterization areas. Because the Hanford Site's elk population consists of one wide-ranging social group (McCorquodale 1985a), no control elk were available for monitoring. However, data collected during 1983-84 (McCorquodale 1985a) provided some comparative temporal data for site characterization elk studies.

The Hanford Site is characterized by shrub-steppe vegetation (Daubenmire 1970). Near the potentially affected Basalt Waste Isolation Project (BWIP) area, plant communities are typically dominated by an understory of grasses, such as bluebunch wheatgrass (Agropyron spicatum), Sandberg's bluegrass (P0a sandbergii), or cheatgrass brome (Bromus tectorum), and an overstory of big sagebrush (Artemisia tridentata) (Rickard 1988). Because of past range fires, big sagebrush has been eliminated from large areas of the Hanford Site. Several other species of grasses and numerous forb species are commonly associated with the typical dominant grasses, or they may occasionally dominate small areas themsetves as a result of microclimatic, edaphic, or disturbance factors. Riparian vegetation is found along permanent springs in the western and southwestern portions of the Hanford Site (Figure 1).

The Hanford Site receives approximately $16 \mathrm{~cm}$ of precipitation each year (Stone et al. 1983), most of which falls between November and March. The area experiences warm, dry summers, where lengthy droughts are common, and relatively cool winters. 
Ecologically and climatically the Hanford Site represents a unique habitat for a resident herd of elk. Although elk are thought to be historical residents of the shrubsteppe (McCorquodale1985b), they have been absent from the region for at least the last 100 years. 


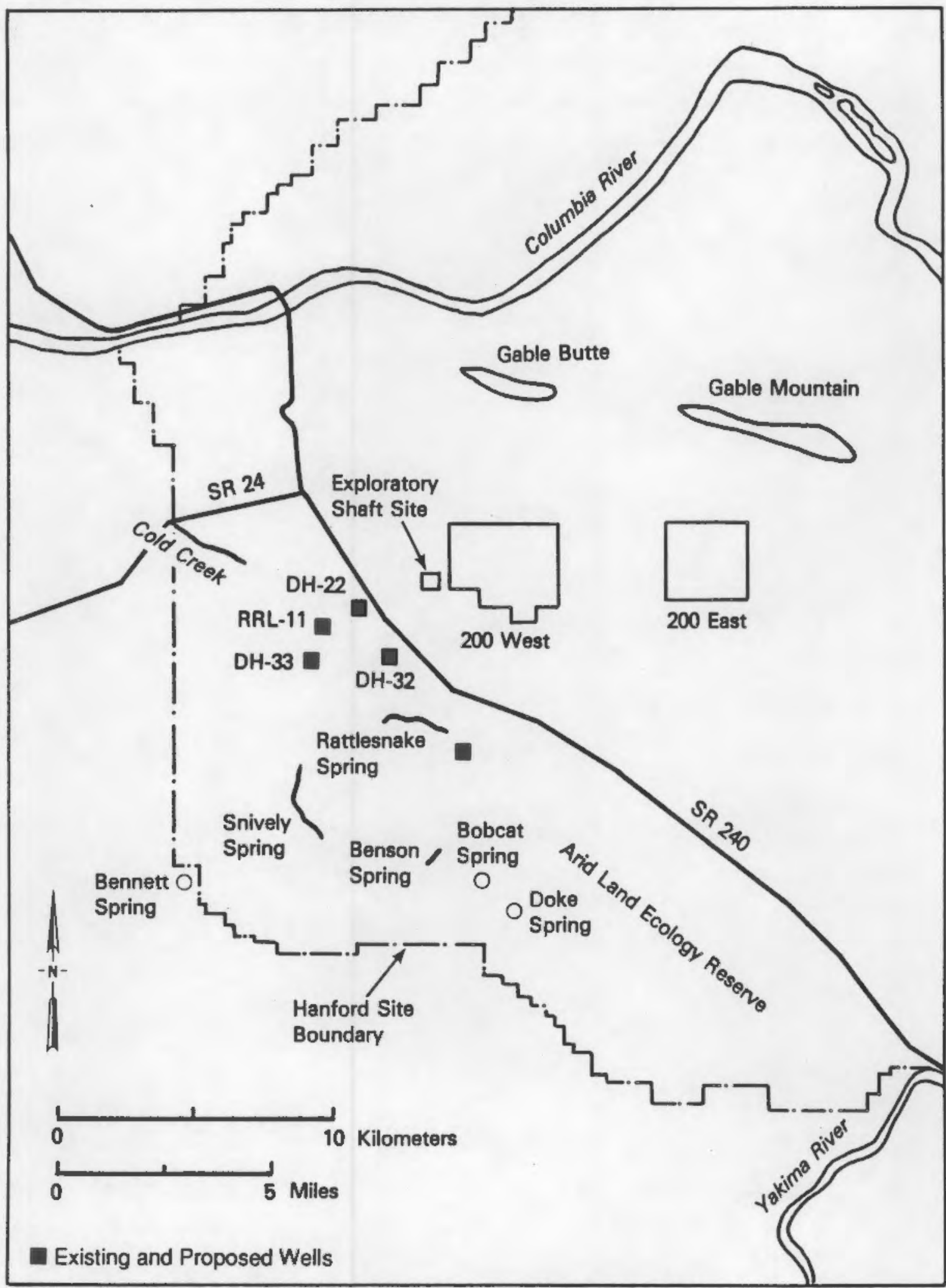

FIGURE 1. Basalt Waste Isolation Project Activity Areas and Geographic Features Near the Deer and Elk Study Area 


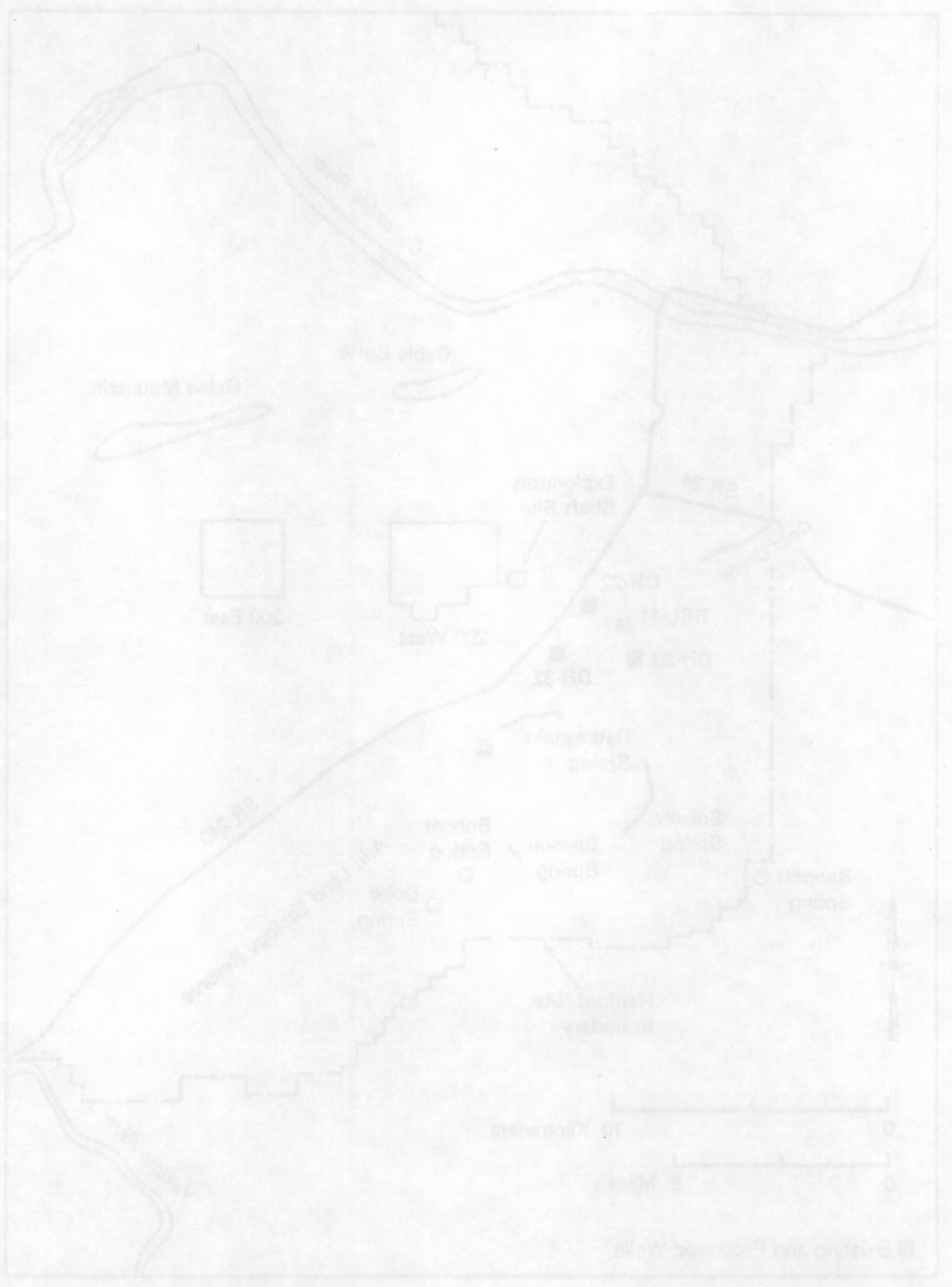




\section{METHODS}

Elk were captured during February and March 1987 by darting them with immobilizing drugs from a Hughes $500 \mathrm{C}$ helicopter (McCorquodale, Eberhardt, and Petron 1988). Immobilizing drugs used included succinylcholine chloride (Sucostrin ${ }^{\circledR}$ ) and xylazine hydrochloride (Rompun ${ }^{\circledR}$ ). Xylazine-induced immobilizations were reversed with yohimbine hydrochlonide (Antagonil(9). Captured elk were ear-tagged, measured, given a prophylactic dose of antibiotic (Flocillin ${ }^{(8)}$ ), fitted with a telemetry collar transmitting within the range of $149-150 \mathrm{MHz}$, and released. A canine tooth was extracted from most immobilized elk for age estimation by cementum annuli (Keiss 1969). All immobilized elk received a local anesthetic (Lidocaine $\left.{ }^{(}\right)$in the gum before tooth extraction.

Mule deer were captured during February and March 1987 by herding them into drive nets with a helicopter (Eberhardt, Hanson, and Cadwell 1982). This technique involved stringing several 30 - to $50-\mathrm{m}$ sections of $2.4-\mathrm{m}$-high nylon netting across foothill canyons. Deer were then herded short distances to the nets by the helicopter. Once entangled in the net, the deer were quickly subdued and blindfolded. Each adult female was fitted with colored ear tags and a radio collar transmitting within a range of 149-150 MHz, and then released. Deer estimated to be <18 months of age were released without marking. Emphasis was placed on radio marking fomale deer because it was difficult to properly fit males with collars because of the swelling of their necks during the breeding season.

Radio-equipped deer and elk were relocated once weekly from fixed-wing aircraft. Most flights were conducted in the early-morning hours. Parallel four-element yagi antennae were strut-mounted on a Cessna 172 aircraft. Tracking procedures followed those described by Gilmore et al. (1981). Radio-equipped animals were tracked until they were visually located or until an exact location could be determined with the radio-tracking equipment. A LORAN C navigational system was used to estimate the animal's cartesian position (latitude/longitude) once it was located. Error in relocating marked animals from the air was estimated to be $372 \pm 171$ (1 SD) $\mathrm{m}$. A BASIC computer program was used to convert latitude and longitude coordinates to Universal Transverse Mercator (UTM) coordinates (Dodge, Wilkie, and Steiner 1986). Each time an animal was visually located, its activity, the topographic configuration 
and vegetation type it occupied; the number and age/sex classes of all conspecifics; its reaction to the aircraft; and, if possible, the distance to the nearest sizable sagebrush stand were noted.

Radio-equipped animals were also located every $30 \mathrm{~min}$. duning 4- to 8-h ground tracking sessions conducted at least every other week. Observers located in three permanent tracking stations atop prominent topographic points tracked up to 10 animals in synchrony during each tracking session. Antennae arrays consisted of paired four-element yagi antennae mounted 3-5 $\mathrm{m}$ above the ground on a rotatable mast. Attempts were made to alternate the selection of monitored animals from week to week, but were limited by the number of animals transmitting from receivable locations during any given session. Attermpts were also made to sample all portions of the 24-h circadian cycle periodically, but monitoring focused on those hours nearest dusk and dawn, because these species are principally crepuscular (Collins, Urness, and Austin 1978). Triangulated positions of telemetered animals were recorded at each tracking station as an azimuth, with $0^{\circ}=$ true north; a BASIC computer program was used to convert triangulated azimuths to UTM cartesian coordinates (Dodge and Steiner 1986). This computer program also calculated a 95\% confidence ellipse (CE) associated with each location estimate. Angular error in relocating marked animais from the permanent tracking stations was estimated to be approximately $\pm 1^{\circ}$, based on observations of the actual location of marked animals from the towers and blind testing conducted by Crabtree (R. Crabtree, University of ldaho, Moscow, Idaho, personal communication). An additional estimate of ground-tracking error was obtained when a marked deer, positioned $>3.5 \mathrm{~km}$ from the tracking towers, was located 16 times during a tracking session before it was discovered to be dead. Tracking error in this instance was $156 \pm 73$ (1 SD) $\mathrm{m}$.

\section{DATA ANALYSES}

A reduced data set was constructed from all the aerial and ground telemetry relocations for home range and distance analyses. A maximum of one relocation/ marked individual/day was used in the reduced data set to avoid auto-correlation between relocations over time (Swihardt and Slade 1985). All statistical analyses were conducted with Statview 512+ (BrainPower, Inc. 1986) or SAS System (SAS Institute, Inc. 1985) software. 
Home ranges were estimated for marked elk and deer using the minimum convex polygon method (MCP) (Odum and Kuenzler 1955) and $95 \%$ confidence ellipse method (Jennich and Turner 1969). These estimations were based on the reduced telemetry data set. The null hypothesis of no difference in home range size was tested for the following pairwise comparisons: 1) female deer vs. female elk, 2) female elk vs. male elk, 3) female deer accompanied by fawns vs. female deer without fawns, 4) treatment deer vs. control deer. Hypotheses tests were based on MannWhitney $U$ statistics, except when the sample size of one group was less than $40 \%$ of the sample size of the second group. When the sample sizes were grossly different, unpaired t-test statistics were used for hypothesis testing. One female deer that died early duning the study (No. 15) was excluded from hypothesis testing.

The null hypothesis that elk monitored during 1983-84 (McCorquodale 1985a) had the same home range sizes as elk monitored during 1987 was also tested with the Mann-Whitney $U$ test statistic. Home range activity centers (the average cartesian coordinates of an animal's relocation points) were used to test the null hypothesis that elk used the same area in 1987 as they did in 1983-84. This hypothesis test was based on the Mann-Whitney $U$ test statistic. Home range data were obtained from different elk in 1987 than in 1983-84; however, the animals were from the same social group and were randomly selected during both periods.

Seasonal dependence of elk and deer on riparian areas and water was evaluated by calculating the percent of relocations of marked animals that fell within three $2-\mathrm{km}$ distance zones $(0-2,2-4$, and $4-6 \mathrm{~km})$ radiating from all water sources on the study area. Geographical Resources Analysis Support System software (USACE 1987) was used to calculate the distance zones and determine the proportion of animal locations falling within each zone. Locations of marked animals off of the ALE Reserve were eliminated from the analyses because not all sources of available water off the ALE Reserve could be identified. Data from all individuals within a given sex and species class (e.g., female elk) were combined for analysis because insufficient data were available to conduct the analyses on individual animais. Chi-square analyses and Bonferroni confidence intervals were used to evaluate the relationship between distance from water and season (Neu, Byers, and Peek 1974).

The influence of roads and their associated vehicle traffic on elk and deer were evaluated by calculating the percent of relocations of marked animals that fell within 
ten $1-\mathrm{km}$ distance zones radiating from roads on the study area. The analyses followed the same basic procedures described for analyzing elk and deer use of riparian areas, and were performed for paved roads and high-use dirt roads separately. Those dirt roads that were subjectively determined to be used infrequently (less than once a week) were excluded from the analysis.

The mobility of elk and mule deer was evaluated using the average distance moved/hour during the intensive tracking sessions. Distances moved/0.5-h time periods for consecutive 0.5 -h time periods were summed to obtain distance moved/hour. Frequently, especially for elk, more than one radio-marked animal in a single herd was followed during a given tracking session. Because the movement of one animal reflects that of the others in the herd, movement data were retained for mobility analysis from oniy one randomly selected individual. 


\section{RESULTS AND DISCUSSION}

Eleven elk were captured and equipped with radio transmitters (Tabie 1). Two of these elk, which were recaptures of elk marked during a previous study (McCorquodale 1987), had old, nonfunctioning radio transmitters. In addition, four elk with functioning radio transmitters installed in 1985 (McCorquodale 1987) were also included in the study. Thus, 11 fernale and 4 male radio-equipped elk were on the ALE Reserve during this study. The average age of these elk was $7.0 \pm 4.0$ (1 SD) years.

IABLE 1. Elk Radio-Collared on the Hanford Site for BWIP

Date

Captured

$2 / 1 / 87$

$2 / 1 / 87$

$2 / 19 / 87$

$2 / 19 / 87$

$2 / 19 / 87$

$2 / 21 / 87$

$2 / 22 / 87$

$3 / 20 / 87$

$3 / 20 / 87$

$3 / 20 / 87$

$3 / 20 / 87$

$11 / 30 / 85$

$11 / 30 / 85$

$6 / 8 / 85$

$6 / 8 / 85$
Animal Number

110

84

182

29

222

344

204(b)

429

66 (c)

403

49

132 (d)

275

765

825
Age in

January 1987 (yr)

5.6

3.6

2.6 (a)

2.6

9.6

4.6

8.6

4.6

7.6

5.6 (a)

8.6 (a)

16.6

adult(a)

4.6

12.6
Calf

Sex Present

$F$ Yes

M

$M$

F No

F Yes

F Yes

M -

$F \quad$ No

$M \quad-$

F Yes

F Yes

$F$ No

F Yes

F Yes

F No
(a) Age estimated by tooth wear; age of others estimated by cementum annuli.
(b) Old radio collar (No. 180) installed on 6/84.
(c) Old radio collar (No. 320) installed on 11/85.
(d) Oid radio collar (No. 900) installed on $1 / 83$. 
Nineteen adult female deer were captured and equipped with radio transmitters (Table 2). Fourteen of these deer were captured on the western end of the ALE Reserve (Figure 1); the remaining five were caught on the southern end of the ALE Reserve.

The locations of radio-marked elk and deer were obtained during 54 flights. In addition, $128 \mathrm{~h}$ were spent during 18 intensive radio-tracking sessions monitoring the movements of marked eik and deer (Appendix A). A total of 403 aerial and 1,414 ground relocations were made on radio-equipped elk and deer.

IABLE2. Adult Female Mule Deer Captured on the Hanford Site for BWIP

\begin{tabular}{ccc}
$\begin{array}{c}\text { Date } \\
\text { Captured }\end{array}$ & $\begin{array}{c}\text { Animal } \\
\text { Number }\end{array}$ & $\begin{array}{c}\text { Reproductive } \\
\text { Success in 1987 }\end{array}$ \\
\hline $2 / 20 / 87$ & $15(a)$ & \\
$2 / 20 / 87$ & $90(b)$ & 2 fawns \\
$2 / 20 / 87$ & 237 & \\
$2 / 20 / 87$ & 610 & \\
$2 / 20 / 87$ & 645 & 1 fawn \\
$2 / 20 / 87$ & 684 & 1 fawn \\
$2 / 21 / 87$ & 466 & 1 fawn \\
$2 / 21 / 87$ & 527 & 2 fawns \\
$2 / 21 / 87$ & 565 & \\
$2 / 21 / 87$ & 582 & 2 fawns \\
$2 / 21 / 87$ & $864(c)$ & \\
$2 / 21 / 87$ & 921 & \\
$2 / 21 / 87$ & 945 & \\
$2 / 21 / 87$ & 963 & 1 fawn \\
$3 / 21 / 87$ & 448 & \\
$3 / 21 / 87$ & 480 & \\
$3 / 21 / 87$ & 627 & \\
$3 / 21 / 87$ & 703 & \\
$3 / 21 / 87$ & 782 & \\
(a) Found dead on $7 / 23 / 87$. & \\
(b) Found dead on $7 / 23 / 87$. & \\
(c) Killed illegally $9 / 20 / 87$. & \\
& &
\end{tabular}




\section{HABITAT USE}

Aspects of habitat usage by elk and deer investigated during this study included home range use, use of riparian areas and water sources, and the influence of roads and vehicles.

\section{Home Range Use}

Elk

Home range data for marked elk are summarized in Table 3. Male elk had significantly larger elliptical home ranges than did female elk $(t=2.20, d f=13, P=$ 0.02); however, the difference between male elk home range polygons and female elk home range polygons was not significant $(t=1.33$, $d f=13, P=0.10)$. Four male elk were monitored in 1987. Elk Nos. 66 and 204 were mature adults ( 7 yr) whose mean home ranges were less than the mean for female elk; elk Nos. 84 and 182 were young males (3-4 yr) whose mean home range values were $187 \%$ (MCP) and $311 \%$ (CE) of mean home range values for female elk.

The sizes of home ranges of female elk monitored in 1987 were not significantly different from those measured for female elk during 1983-84 [U],11 $=41, P>0.20$ (MCP); $U_{7,11}=51, P>0.20$ (CE)]. Similarly, the sizes of home ranges of male elk monitored during 1987 were not significantly different than those measured in 1983-84 for male elk $\left[U_{3,4}=7, P>0.20\right.$ (MCP and $\left.C E\right)$ ). However, the location of female elk home range centers (mean $X$ and $Y$ coordinates for each individual) had shifted significantly to the west and north by $1987\left[U_{7,11}=72, P<0.001\right.$ (X-Coor); $U_{7,11}=$ $65, P=0.01$ ( $Y$-Coor)]. The location of male elk home range centers had shifted significantly northward by $1987\left(U_{3,4}=12, P=0.05\right)$; however, no significant changes in the location of male elk home range centers were detected on the east-west axis $\left(U_{3,4}=11, P=0.20\right)$.

It is difficult to definitively establish the cause of the home range shift of female elk between 1983-84 and 1987. However, there is some evidence that this shift may be related to changes in human activity on the ALE Reserve. In 1984, a large rainfallsimulation plot was established near Benson Spring (Figure 1). Human activity in this region has dramatically increased in association with experiments conducted on the 
IABLE3. Home Range Sizes $\left(\mathrm{km}^{2}\right)$ for Marked Elk Studied on the Hanford Site in 1987

\begin{tabular}{ccccc} 
Elk No & Sex & Locations $(N)$ & MCP(a) & CE(b) \\
\hline 29 & $F$ & 42 & 163.7 & 358.5 \\
49 & $F$ & 38 & 82.3 & 160.5 \\
110 & $F$ & 41 & 95.8 & 159.9 \\
132 & $F$ & 47 & 181.9 & 281.8 \\
222 & $F$ & 50 & 156.9 & 204.1 \\
275 & $F$ & 22 & 255.7 & 449.5 \\
344 & $F$ & 32 & 144.5 & 296.8 \\
403 & $F$ & 40 & 170.7 & 217.7 \\
429 & $F$ & 23 & 147.0 & 266.7 \\
765 & $F$ & 50 & 106.2 & 140.5 \\
825 & $F$ & 40 & 172.9 & 328.8 \\
\hline Mean \pm 1 SE & & 38.6 & $152.5 \pm 14.4$ & $260.4 \pm 28.8$ \\
& & & & \\
66 & $M$ & 42 & 141.6 & 236.1 \\
84 & $M$ & 17 & 298.0 & 763.9 \\
182 & $M$ & 24 & 273.2 & 856.2 \\
204 & $M$ & 32 & 94.3 & 164.1 \\
\hline Mean \pm 1 SE & & 28.8 & $201.7 \pm 49.6$ & $505.1 \pm 177.7$
\end{tabular}

\footnotetext{
(a) Minimum convex polygon estimate.

(b) $95 \%$ confidence ellipse estimate.
}

experimental plot. In addition, three BWIP drilling pads $[\mathrm{DH}-32, \mathrm{DH}-33$, Benson Ranch Well (Figure 1)] were established in the westem part of the ALE Reserve in 1986, and ecological studies of coyotes on the ALE Reserve were initiated in 1985 and continued through 1987. Research activity associated with these studies has led to an increase in vehicle traffic in the midwestern part of the ALE Reserve. Because elk are known to be sensitive to human activity, particularly vehicle traffic (Witmer and deCalesta 1985), increased human activity on the ALE Reserve may have prompted the resident elk population to shift their use westward where human disturbance is less frequent. Elk use of the remote western part of Rattlesnake Mountain appeared to be particularly high in 1987 relative to $1983-84$. 


\section{Deer}

Home range data for marked deer on the Hanford Site during 1987 are summarized in Table 4. The home ranges of marked female deer were significantly smaller than the home ranges of marked female elk $\left[U_{11,18}=198, P<0.0005\right.$ (MCP and $(E)$ ]. There appeared to be no difference between home range sizes of female deer with fawns and those without $\left[\mathrm{U}_{8,10}=48, P>0.20\right.$ (MCP and CE)]. The elliptical home ranges of treatment deer were significantly smaller than those estimated for control deer $(t=2.02, d f=16, P=0.03)$; the difference in home range polygon sizes between treatment and control deer was nearly significant $(t=1.55, d f=16, P=0.07$ ). The lower mobility of deer relative to elk and their lower sensitivity to disturbances was reflected in their home range pattems and linear movement rates (see section on movements). The smalier home ranges of treatment deer relative to control deer may reflect somewhat better habitat quality on the western part of the ALE Reserve relative to the eastern part. Natural springs and associated riparian vegetation are more common on the western part of the ALE Reserve than on the eastern part. It is tenuous to base such a conclusion on one year's data and a small sample size; however, treatment deer appeared to produce more fawns per doe $(0.75)$ than did control deer $(0.40)$ in 1987 , lending some credence to this hypothesis.

\section{Use of Riparian Areas and Water Sources}

Eight sources of free water are availabie to elk and deer on the ALE Reserve (Figure 1), seven perennial and one intermittent. These sources include five small perennial springs and two extensive perennial springs, Rattlesnake Spring and Snively Spring. In addition, an intermittent stream, Cold Creek, is available only during the early spring nunoff. Riparian areas are attractive to elk and deer because of the water and the succulent forage available during the dry summer and early fall months.

\section{Elk}

During this study, Rattlesnake Spring was the most intensely used water source by elk on the ALE Reserve. The lower end of Snively Spring (Figure 1) appeared to be used second in importance. 
IABLE 4. Home Range Sizes $\left(\mathrm{km}^{2}\right)$ for Marked Female Deer Studied on the Hanford Site in 1987

\begin{tabular}{|c|c|c|c|c|}
\hline Deer No. & $\begin{array}{l}\text { Number of } \\
\text { Relocations }\end{array}$ & $M C P(a)$ & $\mathrm{CE}(\mathrm{b})$ & Group $(c)$ \\
\hline 90 & 22 & 8.6 & 21.6 & $\mathrm{~T}$ \\
\hline 237 & 41 & 34.0 & 56.7 & $T$ \\
\hline 448 & 26 & 44.7 & 92.8 & $c$ \\
\hline 466 & 24 & 20.7 & 41.7 & $T$ \\
\hline 480 & 18 & 40.4 & 104.3 & C \\
\hline 527 & 18 & 33.3 & 79.3 & $T$ \\
\hline 565 & 35 & 5.8 & 8.8 & $\mathrm{~T}$ \\
\hline 582 & 23 & 9.0 & 19.0 & $T$ \\
\hline 610 & 21 & 16.4 & 29.6 & $\mathrm{~T}$ \\
\hline 627 & 23 & 22.4 & 47.1 & $C$ \\
\hline 645 & 32 & 34.0 & 60.1 & $T$ \\
\hline 684 & 29 & 13.0 & 19.2 & $T$ \\
\hline 703 & 28 & 15.8 & 29.6 & $c$ \\
\hline 782 & 26 & 20.1 & 34.0 & $c$ \\
\hline 864 & 25 & 5.6 & 9.1 & $T$ \\
\hline 921 & 17 & 5.7 & 11.1 & $T$ \\
\hline 945 & 31 & 17.6 & 27.6 & $\mathrm{~T}$ \\
\hline 963 & 38 & 37.6 & 54.6 & $T$ \\
\hline $\operatorname{san} \pm 1 S E$ & 26.5 & $21.4 \pm 3.0$ & $41.4 \pm 6.7$ & \\
\hline
\end{tabular}
(a) Minimum convex polygon estimate.
(b) $95 \%$ confidence ellipse estimate.
(c) $\mathrm{T}=$ treatment deer; $\mathrm{C}=$ control deer.

On the basis of the telemetry relocations, elk usage of three distance zones radiating from water sources $(0-2,2-4$, and $4-6 \mathrm{~km})$ was not in proportion to the availability of these zones (i.e., the area of the zones) during the summer and fall for females and during the summer for males (Table 5). During the summer and fall, females preferred to spend a greater proportion of their time in the zone closest to water and avoided areas distant from water (Figure 2, Table 5). During the winter, females used all three zones in proportion to their availability. It is believed that the unequal use of these distance zones reflects the changing dependency of female elk 
IABLE 5. Summary of the Use of Three Distance Zones from Water by Elk and Deer During the Summer, Fall, and Winter on the ALE Reserve

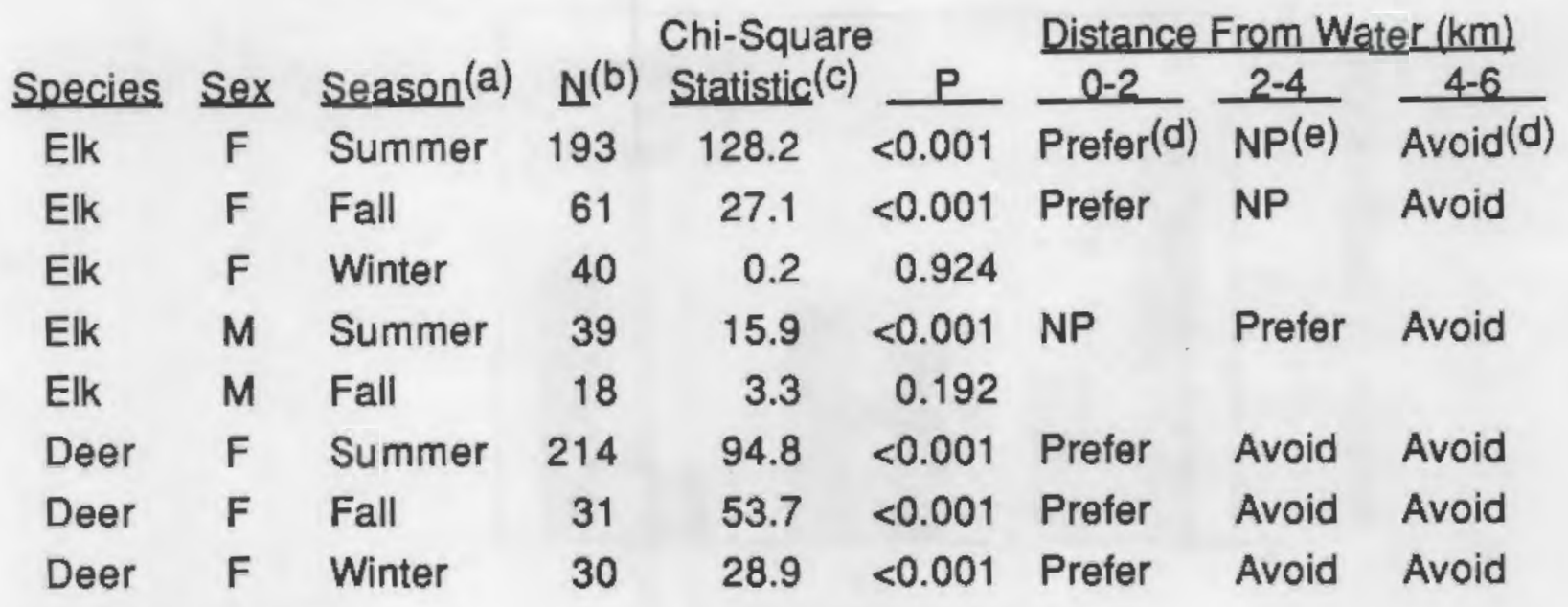

(a) Summer $=$ June-Aug, Fall $=$ Sept-Oct, Winter $=$ Nov-Dec.

(b) Number of relocations.

(c) Test of the hypothesis that the proportion of animal relocations in a given distance zone is not significantly different than the proportional land area within that zone; degrees of freedom for the test $=2$.

(d) When the chi-square test was significant, a Bonferroni simultaneous confidence interval test (Neu, Byers, and Peek 1974) was conducted to test whether a given distance zone was preferred or avoided.

(e) No preference (i.e., avoidance or attraction) was detected.

on riparian areas. During the dry summer and early fall months riparian areas provide the only source of succulent vegetation on the ALE Reserve. In addition, the water requirements of females with calves are elevated during the summer because of the physiological demands of lactation (MacFarlane and Howard 1972).

Male elk appeared to be less dependent than females on riparian areas (Figure 2, Table 5). During the summer, males demonstrated a preference for areas more distant from water sources than did females (Table 5). During the fall, all three distance zones were used by males in approximately equal proportion to their availability. Insufficient relocations were made on the males during the winter to evaluate their dependency on riparian areas. 


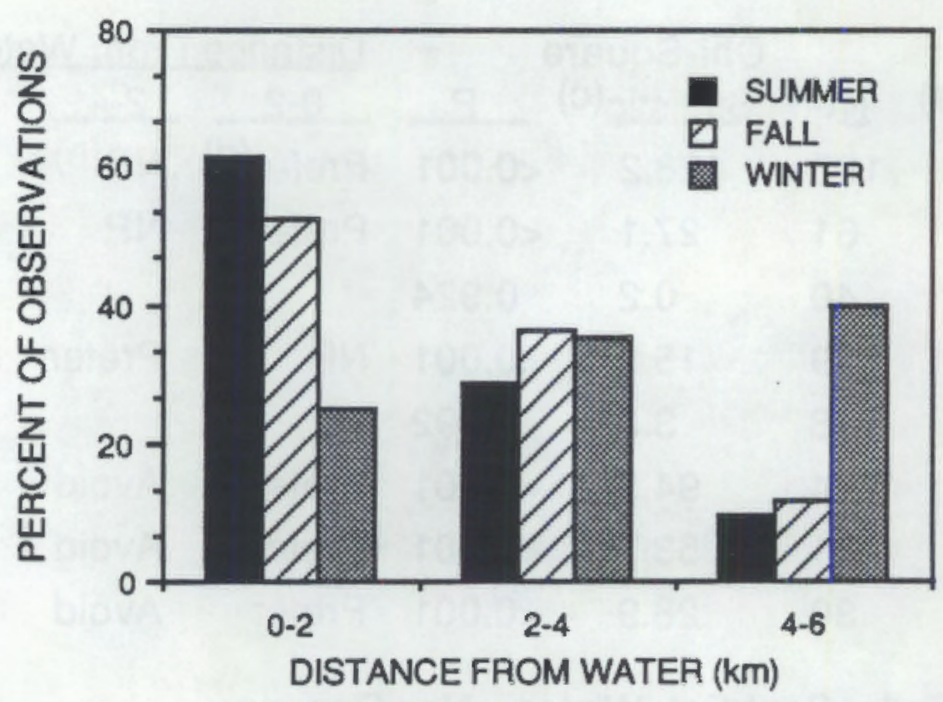

(a) Female Elk

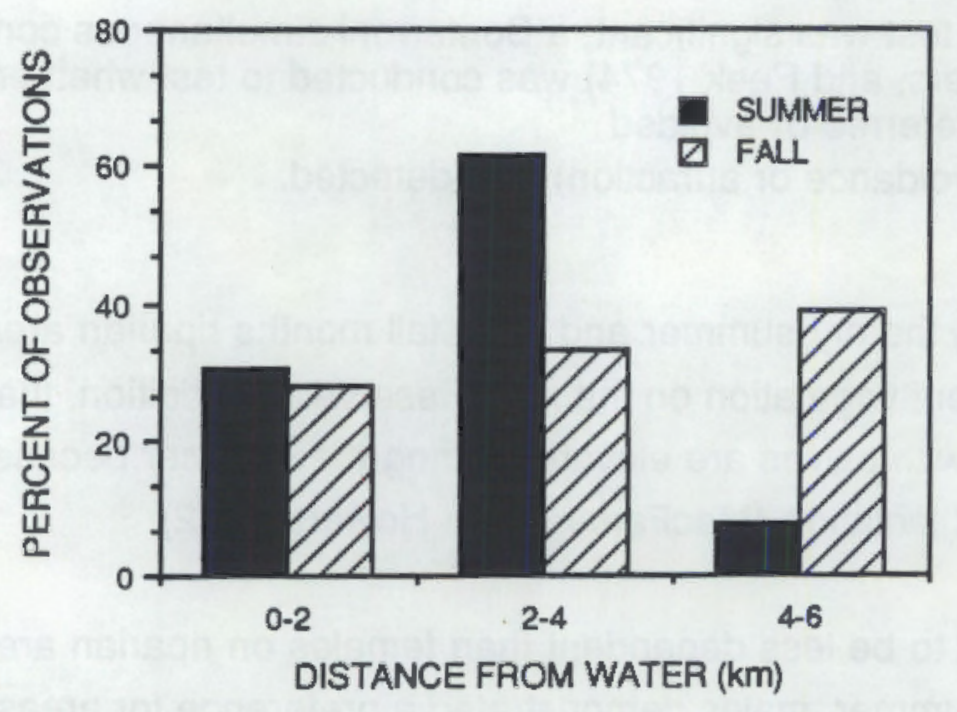

(b) Male Elk

FIGURE2. Comparison of the Proportion of Relocations of Radio-Marked Elk that Fall Within Three Distance Zones Radiating from All Available Water Sources on the ALE Reserve 
Elk are a highly mobile species capable of moving comparatively long distances to reach water. Male elk demonstrated this capability in that they spent relatively little time during the dry summer and fall months near available water sources. In contrast, females spent a considerable amount of time near water sources during these months, which is probably because of both the increased water demands resulting from lactation and a need to maintain a high energy intake during lactation. In addition, the presence of calves may also restrict the mobility of adult female elk.

\section{Deer}

Usage by deer of the three distance zones radiating from water $(0-2,2-4$, and 4$6 \mathrm{~km}$ ) was not in proportion to availability of these zones (i.e., the area of the zones) (Table 5). During all seasons, deer appeared to prefer the $0-2-\mathrm{km}$-distance zone and avoid areas remote from water.

Deer were found consistently closer to water than were elk (Figures 2 and 3). This finding probably reflects the comparative mobility of the two species; that is, elk are capable of moving greater distances to reach water than are deer. In addition, deer may restrict their activities closer to water, and the associated succulent forage, because they are less capable than elk of digesting dry matter (Mould and Robbins1982). As a result, the availability of free water may constrain the usage of the study area more for deer than elk during the dry summer and early fall months. Unlike elk, the population of deer on the ALE Reserve did not appear to favor any particular water source, but appeared to be present in the vicinity of all available water sources. Individual deer tended to remain in the vicinity of one or two water sources during the summer and fall.

\section{Influence of Roads and Vehicles}

The influence of roads and vehicles on the movement and habitat use of elk and deer have been of considerable interest to wildlife managers (Pedersen, Adams, and Skovlin 1979; Lyon 1979). An increase in vehicle use of roads within the study area was expected with the proposed development of BWIP. Relocation data from radio-equipped elk and deer were used to evaluate and obtain background information on the influence of roads and vehicles on these species before BWIPassociated increases in road usage. 


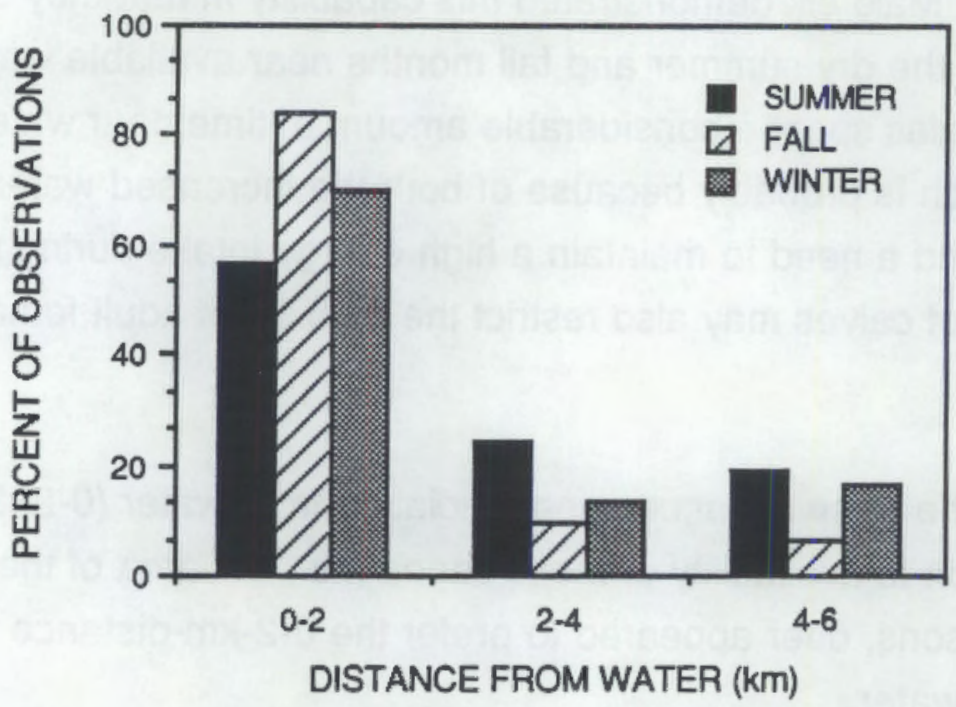

FIGURE 3. Comparison of the Proportion of Relocations of RadioMarked Deer that Fall Within Three Distance Zones Radiating from All Available Water Sources on the ALE Reserve

\section{Elk}

Clear differences in the response of radio-equipped elk to dirt and paved roads were observed (Figure 4). Elk approached dirt roads more closely than they did paved roads, where the volume of traffic was comparatively high.

Temporal differences were also noted in the distribution of elk relative to both paved and dirt roads. During the early morning, late evening, and nighttime hours (during all but $0800-1730 \mathrm{~h}$ ), the distribution of elk relocations shifted closer to the roads than during midday (0800-1730 h), indicating an increased tolerance by elk of roads and vehicles at night (Figure 4). Vehicle traffic on both types of roads was thought to be less during the night than during the day.

\section{Deer}

A similar type of analysis for deer indicated no clear relationship between deer distribution and roads. This was probably because of the relatively small home range size of deer compared with elk. The final distribution of relocations relative to distance from roads was more a reflection of where the deer were originally captured and the varying sampling intensities for each deer. 

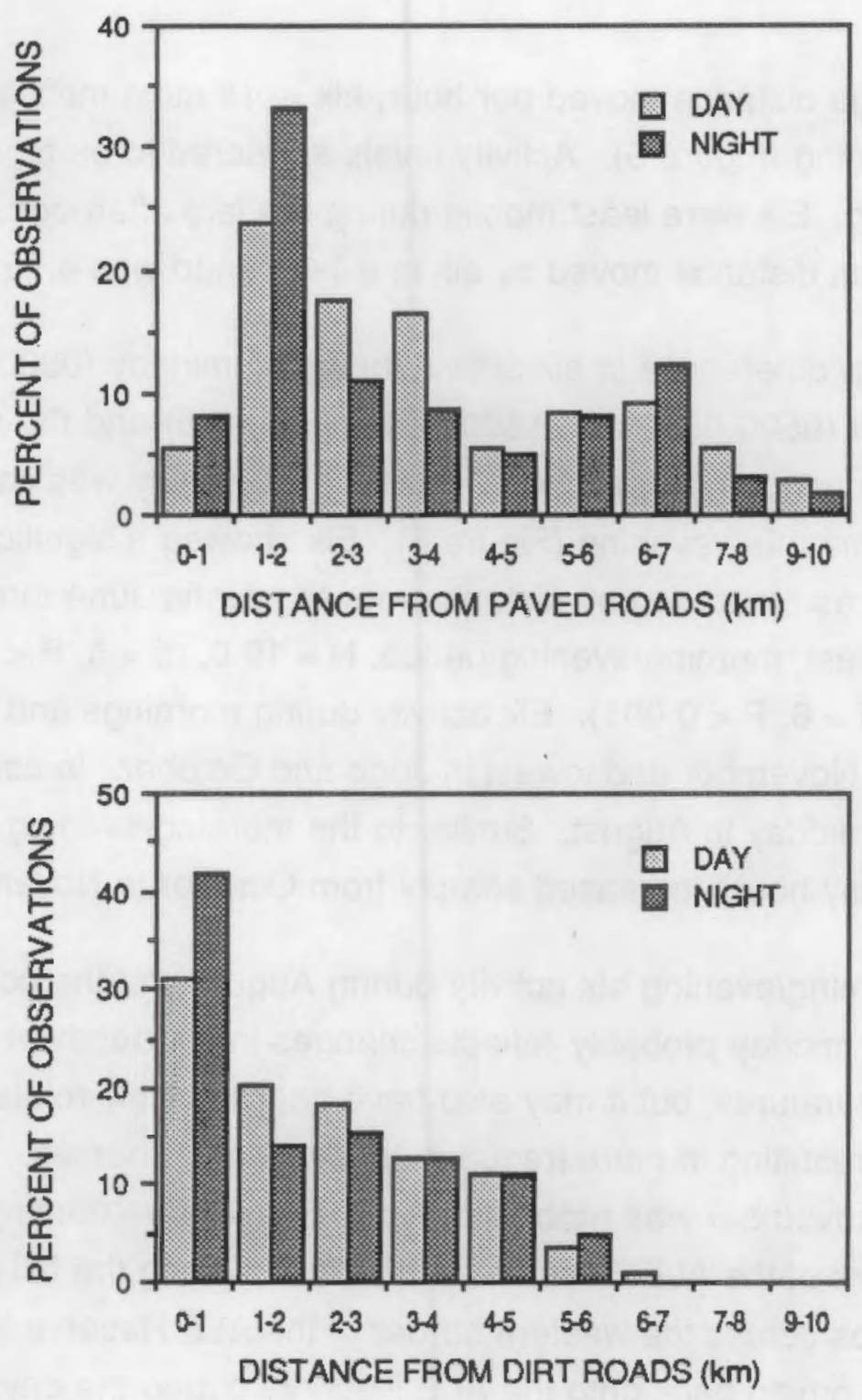

FIGURE 4. Distribution of Relocations of Radio-Equipped Elk Relative to Distance from Paved and Dirt Roads by Time of Day 


\section{MOVEMENTS}

\section{Elk}

Based on the average distance moved per hour, elk were most mobile during early morning and late evening (Figure 5). Activity levels appeared to be higher in the evening than in the morning. Elk were least mobile during the late afternoon, from 1400-1700 h. The maximum distance moved by elk in a 1-h period was $4.75 \mathrm{~km}$.

Because of the sharp differences in elk activity between midday (0900-1700) and morning/evening hours (0500-0800 and 1800-2200) (Figure 5) and the unequal sampling during these time periods (Appendix A), monthly elk activity was compared separately for midday and morning/evening (Figure 6). Elk showed a significant change in monthly activity, as measured by distance moved, during June through December (Kruskal-Wallis test, morning/evening period: $H=19.0$, df $=6, P<0.01$; midday period: $H=39.5, \mathrm{df}=6, \mathrm{P}<0.001$ ). Elk activity during mornings and evenings was highest in August and November and lowest in June and October. In contrast, elk activity was lowest during midday in August. Similar to the morning evening period, elk activity during the midday hours increased sharply from October to November.

The increase in morning/evening elk activity during August and the concomitant decrease in activity during midday probably reflects changes in elk behavior because of increasing daytime temperatures, but it may also have been partially related to increased water demands resulting in more frequent trips to water sources. The increase in elk activity in November was probably related to intensive hunting pressure around the borders of the ALE Reserve at this time. During the fall and early winter, elk made nightly trips across the western border of the ALE Reserve to forage in irrigated fields and were driven back onto the ALE Reserve during the daytime by hunters. Because of the dry fall, these fields represented one of the few available sources of green, succulent forage. The increase in overall elk activity in November may have also been partially related to breeding activities, although the majority of this breeding took place before November.

No difference was noted in the level of activity for male and female elk from June through October; however, male activity was significantly greater than female activity during peak activity hours in November-December (Table 6). Both sexes showed a sharp increase in activity in November. 


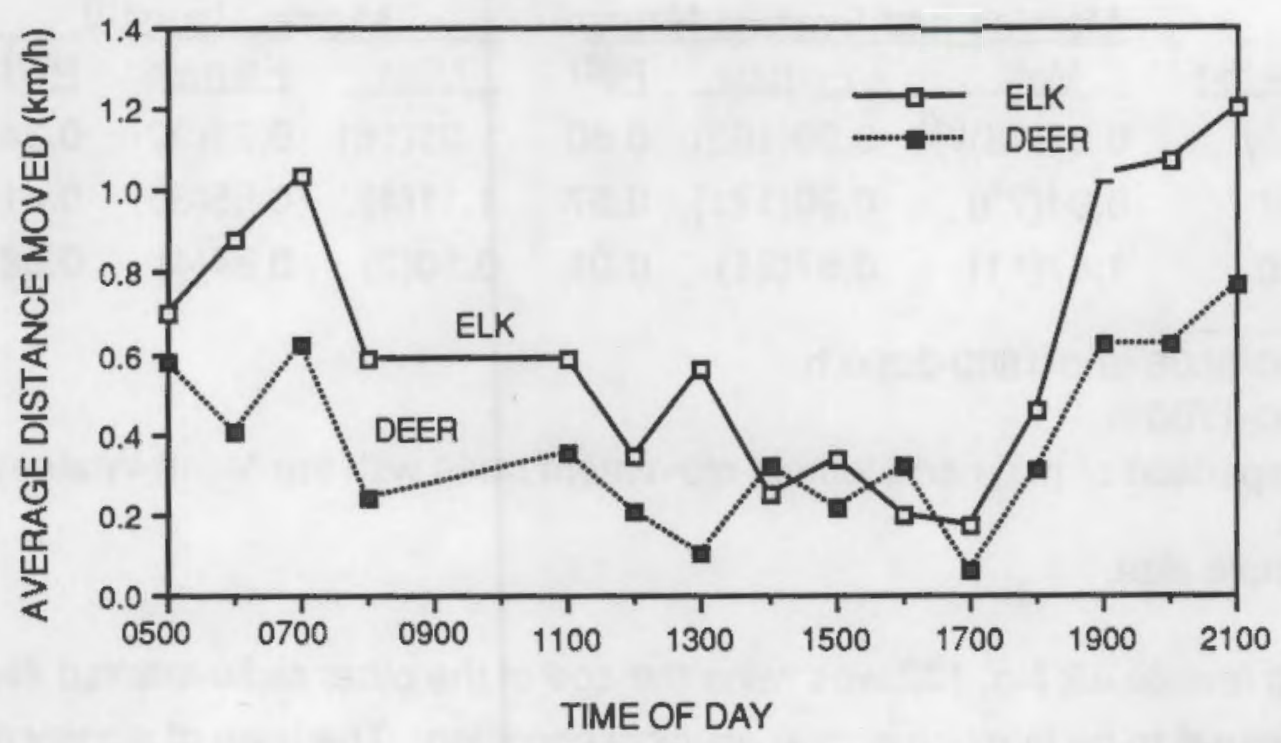

FIGURE 5. Comparison of Daily Activity Patterns of Elk and Mule Deer on the Hanford Site as Measured by Average Distance Moved

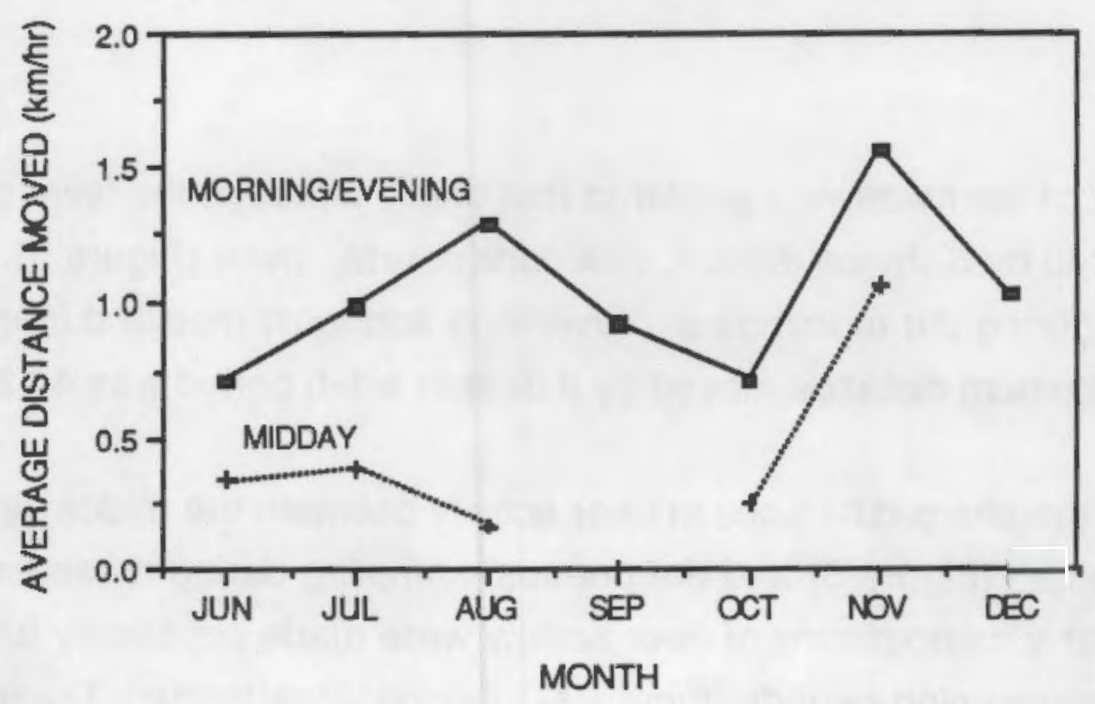

FIGURE 6. Comparison of Monthly Activity Patterns of Elk on the Hanford Site During Morning/Evening (0500-0800 and 1800-2200 h) and Midday (0900-1700 h) as Measured by Average Distance Moved 
IABLE 6. Average Distance Moved $(\mathrm{km} / \mathrm{h})$ by Male and Female Elk by Season on the Hanford Site

\begin{tabular}{|c|c|c|c|c|c|c|}
\hline \multirow[b]{2}{*}{ Time Period } & \multicolumn{3}{|c|}{ Morning and Evening Hours (a) } & \multicolumn{3}{|c|}{ Midday Hours $(\mathrm{b})$} \\
\hline & Male & Female & $\mathrm{P}^{(\mathrm{c})}$ & Male & Eemale & $\mathrm{P}^{(\mathrm{c})}$ \\
\hline 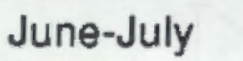 & $0.85(18)(d)$ & $0.99(162)$ & 0.80 & $1.05(16)$ & $0.28(92)$ & 0.34 \\
\hline & $0.94(73)$ & $0.90(171)$ & 0.57 & $1.11(4)$ & $0.85(38)$ & 0.41 \\
\hline V-Dec & $1.87(11)$ & $0.67(21)$ & 0.01 & $0.10(2)$ & $0.84(4)$ & 0.08 \\
\hline
\end{tabular}

(a) 0500-0800 and 1800-2200 h.

(b) $0900-1700 \mathrm{~h}$.

(c) Comparison of male and female movement rates with the Mann-Whitney $U$ test.

(d) Sample size.

Adult female elk No. 132 was twice the age of the other radio-marked elk (Table 1) and appeared to be in much poorer physical condition. The level of activity of No. 132 was significantly less (Mann-Whitney $U$ test, $P<0.01$ ) than that of other female elk during the fall (midday and evening/morning periods) and the midday summer periods, but no difference $(P=0.31$ ) was noted during the morning/evening period of the summer. Insufficient data were available for making comparisons during the winter period.

\section{Deer}

The mobility of deer was very similar to that of elk, although the level of deer activity, as measured by distance moved, was considerably lower (Figure 5). Deer were most mobile during the mornings and evenings and least mobile during the late afternoon. The maximum distance moved by a deer in a 1-h period was $4.12 \mathrm{~km}$.

Because of the sharp difference in deer activity between the midday and morning/evening hours (Figure 5) and the unequal sampling during these time periods (Appendix A), monthly comparisons of deer activity were made separately for the midday and morning/evening periods (Figure 7). During June through December, deer showed a significant change in activity, as measured by distance moved, during the morning/evening hours (Kruskal-Wallis test; $H=25.6$, df $=6, P<0.001$ ), but not during the midday period $(H=4.6, d f=4, P>0.30)$. In general, the monthly mobility of deer (Figure 5) was very similar to that of elk (Figure 6). An increase in overall deer 


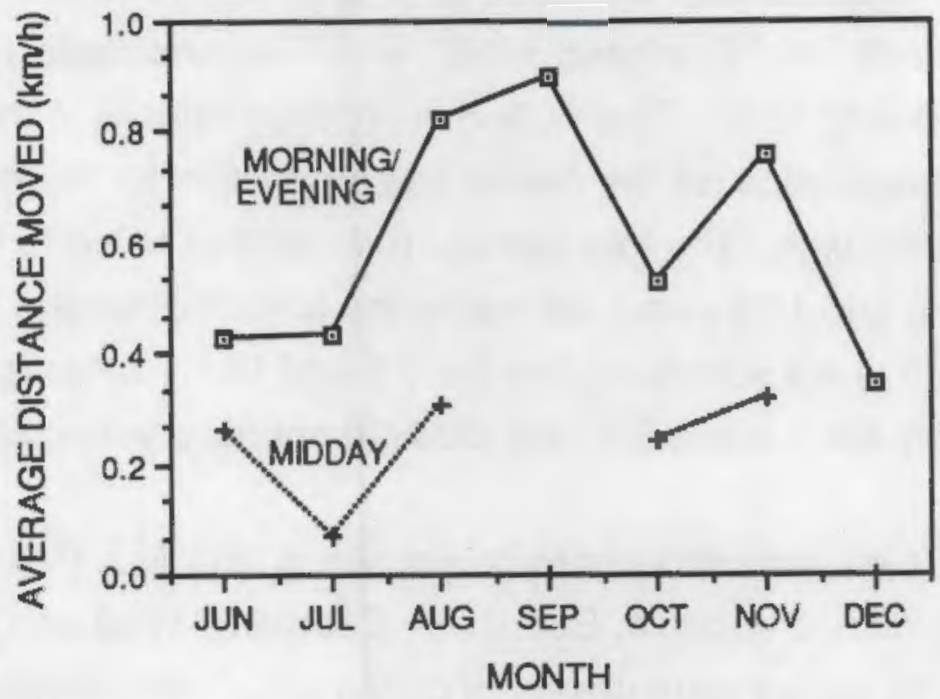

ElGURE 7. Comparison of Monthly Activity Patterns of Mule Deer on the Hanford Site During Morning/Evening (0500-0800 and 1800-2200 h) and Midday (0900-1700 h) as Measured by Average Distance Moved

activity from October to November was also noted for deer; however, deer were seldom located in areas open to hunting. This increase in activity was probably related to breeding. The only apparent difference in activity between the two species was the extension of peak morning/evening deer activity into September, a time when elk activity appeared to decrease.

\section{POPULATION DYNAMICS}

Aspects of population dynamics examined during this study included population size (elk only), reproductive success, and mortality.

\section{Elk}

Elk calves were first observed on the study area on May 26. Of the 11 female elk captured, 7 (64\%) were observed with calves in May and June (Table 1). Ten of these elk were older than 1.5 years during the breeding season of 1986; one was 1.5 years old. This results in a rate of 0.70 calves/adult female ( $>1.5$ years old) in 1987 . 
Reproductive success of yearling elk is generally low (McCorquodale, Eberhardt, and Eberhardt 1988); however, the productivity for adult females (>1.5 years) on the ALE Reserve for the period $1982-86$ was estimated to be 0.91 calves/adult female (McCorquodale, Eberhardt, and Eberhardt 1988), which is considerably higher than the number observed during 1987 . This finding is probably related to the small sample of marked females, because the overall calf production for the herd (see below) was comparatively high. The four marked females that failed to have calves in 1987 were $1.5,2.5,3.5$, and 16.5 years old during the breeding season of 1986.

Because of their ages, it is not surprising that the 1.5 and 16.5 year olds failed to have calves. The reason why the 2.5 and 3.5 year olds did not have young is unknown.

Approximately 74 elk were thought to be present on the ALE Reserve at the beginning of the study (McCorquodale, Eberhardt, Eberhardt 1988 and unpublished data). A maximum of 26 calves were observed during aerial relocations of radiomarked elk (flight on 9/3/87, Appendix A). During this flight, one radio-marked adult cow, which was known to have a calf, was not relocated; therefore, at least 27 calves were born on the study area in May and June. This results in an estimated 101 animals on the ALE Reserve before the hunting season began, assuming no mortality. A maximum of 92 elk were observed during the aerial surveys (9/3/87, Appendix A). During this flight, one marked adult female with a calf was missed; therefore, the maximum known number present would have been 94 . Presumably, either some elk died or, more likely, a few unmarked individuals also were missed during the survey.

A minimum of 14 elk were killed during the late summer and fall of 1987. These elk were killed on privately owned lands surrounding the ALE Reserve during several localized "hot spot" hunts and a 1.5-month-long regular hunting season during October and November. The hot spot hunts were brief hunts organized by the Washington Department of Wildlife to alleviate damage caused by the elk on adjacent irrigated farm land during the dry months of August-October. Two of the $15(8 \%)$ radioequipped elk (Nos. 84 and 49) were killed during the hunting seasons.

\section{Deer}

Reproductive success of marked deer was monitored duning weekly aerial relocations and from the ground (Table 2). In general, reproductive success appeared to be low, with only eight of the $17(47 \%)$ marked females (excludes Nos. 15 and 90 
because of their deaths) observed with fawns. Because of the secretive nature of fawns during the first few weeks of life, the majority of the fawns of marked does were often not observed until they were at least 1 -month old, even though intensive efforts were made to try and observe all the marked deer as soon as possible after the fawning season (late May-early June). Based on data on high pregnancy rates of deer collected elsewhere on the Hanford Site (Eberhardt, Hanson, and Cadwell 1982), it is believed that most of the does marked during this study were probably pregnant. Presumably, relatively high fawn mortality occurred during the first few weeks of life as was noted by Steigers and Flinders (1980) along the Columbia River on the Hanford Site.

Four of the $20(20 \%)$ radio-marked deer died during the study period (Table 2). Two adult females were found dead on July 23,1987 . The cause(s) of death could not be determined in either instance. However, because the deaths occurred 1.4 months after capture, they are not believed to have been related to the original capture and handling. One additional adult deer was killed illegaliy on $9 / 20 / 87$, and the fourth deer was killed by a vehicle on about $11 / 20 / 87$. 


\section{CONCLUSIONS ENVIRONMENTALIMPACT CONSIDERATIONS}

The level of engineering and construction activity associated with BWIP during 1987 was not sutficient to directly assess the responses of elk and deer to disturbance; however, the results of this study suggest some general considerations regarding minimizing and/or mitigating impacts on the Hanford elk and deer populations from engineering activities.

Areas near water are particularly valuable habitats to elk and deer in the arid Hanford environment. The areas near water, which are scarce on the site, provide drinking water and succulent forage. Disturbances near niparian zones may represent one of the greatest potential impact routes to elk and deer on the Hanford Site. When attempting to minimize impacts to elk and deer from large-scale engineering activities on the Hanford Site, consideration should be given to avoiding, as much as is practicable, riparian areas. When activities must be conducted near riparian areas, it may be beneficial to increase the security of other riparian areas to provide elk and deer with alternative use areas. This could be accomplished with traffic restrictions or road closures near niparian areas. Limiting disturbances near niparian areas between dusk and dawn may also reduce the impact of human activities on elk and deer using these areas. Mitigation by establishing manmade water catchments could replace lost drinking areas; but will not replace lost succulent forage that may be critical to elk and deer in these arid habitats.

There is some evidence that human activities initiated since 1984 also have led to changes in the distribution of elk use on the Hanford Site. Elk are less able to habituate to human activity on the Hanford Site than deer. Further increases in human activity in the western part of the ALE Reserve may lead to further changes in elk use patterns. These changes could be reflected in increasing use by elk of adjacent private lands. 


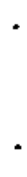




\section{REFERENCES}

BrainPower, Inc. 1986. Statview 512t: The Professional Graphics Statistics Utility. BrainPower, Inc. Calabasas, California.

Collins, W. B., P. J. Urness, and D. D. Austin. 1978. "Elk Diets and Activities on Different Lodgepole Pine Habitat Segments." L. Wild. Manage. 42:799-810.

Daubenmire, R. 1970. "Steppe Vegetation of Washington." Wash. Agric. Exp. Stn. Tech. Bull. 62. $131 \mathrm{pp}$.

Dodge, W. E., and A. J. Steiner. 1986. XYLOG:A Computer Program for Field Processing Lecations of Radio-tagoed Wild life. U.S. Fish and Wildlife Tech. Rep. No. 4. Washington, D.C. $22 \mathrm{pp}$.

Dodge, W. E., D. S. Wilkie, and A. J. Steiner. 1986. UTMTEL:A Laptop Computer Program for Location of Telemetry "Finds" Using LORANC. Massachusetts Cooperative Wildlife Research Unit, Amherst. 21 pp.

Eberhardt, L. E., E. E. Hanson, and L. L. Cadwell. 1982. Analysis of Radionuclide Concentrations and Movement Patterns of Hantord Site Mule Deer. BNWL-4420, Pacific Northwest Laboratory, Richland, Washington.

Gilmore, D. S., L. M. Cowardin, R. L. Duval, L. M. Mechlin, C. W. Shaiffer, and V. B. Kuechle. 1981. Procedures for the Use of Aircraft in Wildlife Biotelemetry Studies. U.S. Dept. Interior Resour. Publ. No. 140, Washington, D.C. 19 pp.

Jennnich, R. I., and F. B. Turner. 1969. "Measurement of Noncircular Home Range". L. Theor. Biol. 22:277-337.

Keiss, R. E. 1969. "Comparison of Eruption-Wear Patterns and Cementum Annuli as Age Criteria in Elk". L.Wild, Manage. 33:175-80.

Lyon, L. J. 1979. "Habitat Effectiveness for Elk as Influenced by Roads and Cover." لـ. For. 77:658-660.

MacFarlane, W. V., and B. Howard. 1972. "Comparative Water and Energy Economy of Wild and Domestic Mammals." Symp. Zool. Soc. London. 31:261-296.

McCorquodale, S. M. 1985a. The Ecology of Elk (Cervus elaphus) in the ShrubSteppe of Washington. M.S. Thesis, University of Washington, Seattle, Washington.

McCorquodale, S. M. 1985b. "Archaeological Evidence of Elk in the Columbia Basin." Northwest Sci. 59:192-197.

McCorquodale, S. M. 1987. "Fall-Winter Habitat Use by Elk in the Shrub-Steppe of Washington." Northwest Sci. 61:171-173. 
McCorquodale, S. M., L. E. Eberhardt, and S. E. Petron. 1988. "Helicopter Immobilization of Elk in Southcentral Washington." Northwest Sci. 62:49-52.

McCorquodale, S. M., L. L. Eberhardt, and L. E. Eberhardt. 1988. "Dynamics of a Colonizing Elk Population." \لWildl, Manage. 52:309-313.

Mould, E. D., and C. T. Robbins. 1982. "Digestive Capabilities in Elk Compared to White-Tailed Deer." J.Wild. Manage. 46:22-29.

Neu, C. W., C. R. Byers, and J. M. Peek. 1974. "A Technique for Analysis of Utilization-Availability Data." J.Wild. Manage. 38:541-545.

Nuclear Regulatory Commission (NRC). 1976. Breparation of Environmental Reports for Nuclear Power Stations. Regulatory Guide 4.2, Rev. 2, U.S. Nuclear Regulatory Commission, Washington, D.C.

Odum, E. P., and E. J. Kuenzler. 1955. The Measurement of Territory and Home Range Size in Birds." Auk 72:128-137.

Pedersen, R. J., A. W. Adams, and J. Skovlin. 1979. Elk Management in Blue Mountain Habitats. Research Report, Oregon Dept. Fish and Wildlife, Portland, Oregon.

Rickard, W. H. 1988. Natural Vegetation at the Proposed Reference Repository Location in Southeastern Washington. PNL-6402, Pacific Northwest Laboratory, Richland, Washington.

SAS Institute, Inc. 1985. SAS User's Guide. SAS Institute Inc., Cary, North Carolina.

Steigers, W. D., Jr., and J. T. Flinders. 1980. "Mortality and Movements of Mule Deer Fawns in Washington." J.Wild._Manage. 44:381-388.

Stone, W. A., J. M. Thorp, O. P. Gifford, and D. J. Hoitink. 1983. Climatelegical Summary for the Hanford Area. PNL-4622, Pacific Northwest Laboratory, Richland, Washington.

Swihart, R. K., and N. A. Slade. 1985. "Influence of Sampling Interval on Estimates of Home-Range Size." ل.Wild, Manage. 49:1019-1024.

U.S. Army Corps of Engineers (USACE). 1987. GRASS Users and Programmers Manual for the Geographical Resources Analysis Support System. USA - CERL ADP Report N-87/22. Construction Engineering Research Laboratory, Champaign, Illinois.

Witmer, G. W., and D. S. deCalesta. 1985. "Effect of Forest Roads on Habitat Use by Roosevelt Elk." Northwest Sci, 59:122-125. 


\section{APPENDIX A}

\section{SCHEDULE AND SUMMARY OF RADIO-TRACKING}

DATA IN 1987 
IABLE_A.1. Schedule of Intensive Radio-Tracking Conducted on Elk and Deer for the BWIP in 1987

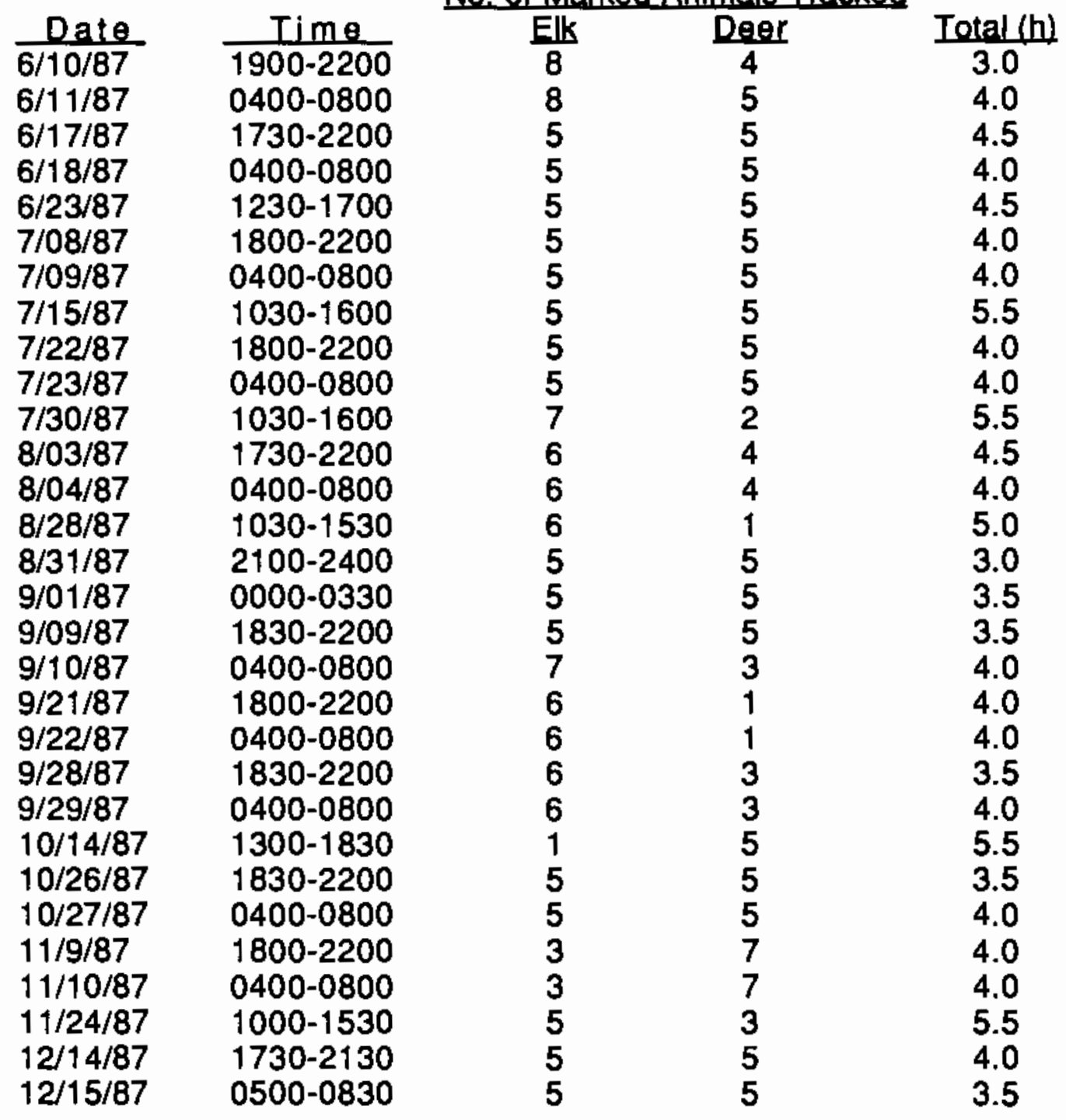


IABLEA.2. Summary of Elk Counts Made During Aerial Relocations of Radio-Marked Elk on the ALE Reserve of the Hanford Site

Total Branch Total Proportion

Date Obsened (a) Cows Calves Antlered Soikes Bulls Relocated(b) $10 / 31 / 86 \quad 63$

$11 / 06 / 86 \quad 42$

$11 / 18 / 86 \quad 64$

$12 / 09 / 86 \quad 41$

$12 / 22 / 86 \quad 71$

$12 / 30 / 86 \quad 42$

$01 / 29 / 87 \quad 44$

$02 / 03 / 87 \quad 62$

$02 / 11 / 87 \quad 39$

$02 / 18 / 87 \quad 69$

$02 / 25 / 87 \quad 50$

$03 / 06 / 87 \quad 59$

$03 / 21 / 87 \quad 32$

$03 / 22 / 87 \quad 20$

$03 / 31 / 87 \quad 53$

$04 / 07 / 87 \quad 34$

$04 / 14 / 87 \quad 44$

$04 / 23 / 87 \quad 46$

$04 / 28 / 87 \quad 41$

$05 / 07 / 87 \quad 15$

$05 / 12 / 87 \quad 25$

$05 / 14 / 87 \quad 17$

$05 / 18 / 87 \quad 37$

$05 / 22 / 87 \quad 4$

$05 / 26 / 87 \quad 39$

$05 / 29 / 87 \quad 9$

$05 / 31 / 87 \quad 21$

$06 / 04 / 87 \quad 20$

$06 / 09 / 87 \quad 27$

$06 / 12 / 87 \quad 47$

$06 / 16 / 87 \quad 46$

$06 / 22 / 87 \quad 54$

$06 / 30 / 87 \quad 44$

$07 / 14 / 87 \quad 50$

$07 / 21 / 87 \quad 35$

$07 / 28 / 87 \quad 39$

$08 / 06 / 87 \quad 48$

$08 / 13 / 87 \quad 69$

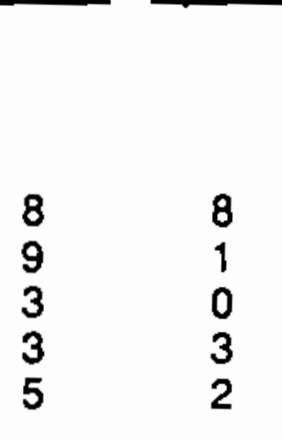

$13 \quad 1.00$

1.00

1.00

$4 \quad 1.00$

$16 \quad 1.00$

$10 \quad 0.80$

$3 \quad 1.00$

$6 \quad 1.00$

$7 \quad 0.86$

$15 \quad 0.86$

$7 \quad 0.55$

1.00

0.20

0.33

0.93

0.73

0.93

0.80

0.93

$3 \quad 0.40$

$3 \quad 0.80$

0.20

0.87

0.13

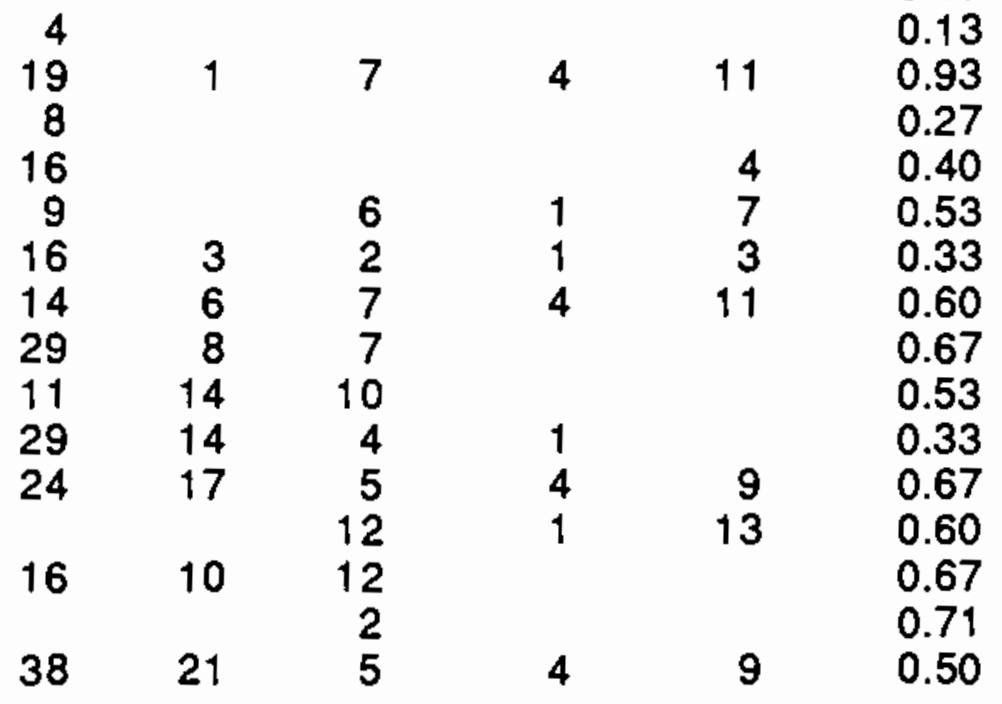


IABLEA.2. (cont.)

Total Branch Total Proportion

Date Observed(a) cows Calyes Antlered Spikes Bulls Relocated(b)

$\begin{array}{llrrrrrr}08 / 19 / 87 & 67 & 29 & 11 & 3 & & 3 & 0.92 \\ 08 / 27 / 87 & 31 & & & 1 & & 1 & 0.85 \\ 09 / 03 / 87 & 92 & 47 & 26 & 14 & 5 & 19 & 0.92 \\ 09 / 18 / 87 & 71 & 41 & 21 & 3 & 2 & 5 & 0.67 \\ 09 / 24 / 87 & 69 & 22 & 13 & 10 & & & 0.92 \\ 10 / 08 / 87 & 82 & & & & & & 1.00 \\ 10 / 22 / 87 & 74 & 42 & 23 & 6 & 3 & 9 & 0.92 \\ 11 / 06 / 87 & 81 & 6 & 9 & 9 & 1 & 10 & 1.00 \\ 11 / 25 / 87 & 47 & 10 & 7 & 5 & 3 & & 1.00 \\ 12 / 07 / 87 & 64 & 33 & 18 & 5 & 3 & 8 & 0.90 \\ 01 / 29 / 88 & 44 & & & 1 & 5 & 6 & 0.90\end{array}$

(a) Elk were classified into specific age and sex classes only when positive identification was made; therefore, the total number of animals recorded may be greater than the sum of the age and sex classes.

(b) Proportion of radio-marked animals relocated. The total number of actively transmitting radios varied between 10 and 15. 


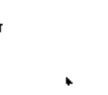




\section{DISTRIBUTION}

No. of

Copies

\section{OFFSITE}

2 DOE Office of Scientific and Technical Information

10 S. M. McCorquodale

Wildlife Resource Management

Yakima Indian Nation

P.O. Box 151

Toppenish, Washington 98948

\section{ONSITE}

DOE Richland Operations Office

E. C. Norman

34 Pacific Northwest Laboratory

L. E. Eberhardt (10)

J. W. Falco

M. J. Graham

R. H. Gray

P. C. Hays

T. L. Page

W. H. Rickard

L. E. Rogers (2)

G. A. Sargeant (5)

J. B. States

J. A. Stottlemyre

J. M. Thomas

S. G. Weiss

R. E. Wildung

Publishing Coordination

Technical Report Files (5) 


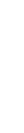

